http://jmscr.igmpublication.org/home/ ISSN (e)-2347-176x ISSN (p) 2455-0450 crossref DOI: https://dx.doi.org/10.18535/jmscr/v8i2.54

\title{
Magnetic Resonance Imaging of Degenerative Disease of theLumbar Spine
}

\author{
Authors
}

\section{Dr Shyamala Javvadi ${ }^{1}$, Dr Kiranmayi Chalasani ${ }^{2}$, Dr Julius N Toppo ${ }^{3}$, Dr Priyanka ${ }^{4}$ \\ ${ }^{1}$ Third Year Post Graduate, ${ }^{2}$ Second Year Post Graduate \\ ${ }^{3}$ Professor and HOD, ${ }^{4}$ Senior Resident}

Department of Radiodiagnosis, Konaseema Institute of Medical Sciences and Research Foundation

Abstract
Introduction: In Low backache patients of 35 to 50 yrs age group, degenerative disc disease was found
to be the most common culprit. The superior soft-tissue contrast resolution of MRI has allowed for
noninvasive detailed anatomic evaluation of the spine without radiation exposure and is considered the
imaging modality of choice for detection of an actual cause of radicular symptoms versus regular age-
related changes. The most commonly affected region is the lumbar spine in acquired degenerative
disease.
Purpose: Role of MRI in the evaluation of the degenerative disc changes in the lumbosacral spine in
patients with low backache.
Materials and Methods: An observational cross-sectional study of degenerative changes of the
lumbosacral spine in patients with low backache referred to the department of Radio-diagnosis, KIMS,
Amalapuram, A.P.
Machine: PhilipsAchieva, 1.5 Tesla MRI machine.
Duration:- For period of two months (1st July2019- 31 August 2019).
Sample size- 186.
Results: Out of a total of 186 patients, the incidence of degenerative disc changes is more in females (
107) compared to males ( 79 ) with a ratio of $1.35: 1$. Most of the patients showed osteophytes, schmorl's
nodes, loss of lumbar lordosis, ligamentum flavum hypertrophy, facet joint arthrosis, endplate (modic)
changes. Disc bulges and herniations were the disc contour abnormalities found in patients with
degenerative disc disease. The most common site for bulges and herniations was the L4-L5 intervertebral
disc level.
Conclusion: MRI is the modality of choice for imaging of degenerative disease of the lumbar spine.
Keywords: MRI, lumbar spine, intervertebral disc,disc degenerative changes.

\section{Introduction}

For imaging of the lumbar spine, the most common reason is low backache. In patients younger than age 45 , low back pain is the leading cause of disability. The causes of the low backache are degenerative/acquired and congenital spinal stenosis, neoplasm, infection, trauma, inflammatory or arthritic processes.
However, the most common culprit was acquired "degenerative" spondylotic changes as the cause of the central canal, subarticular recess, and neuroforaminal compromise ${ }^{[1]}$. A combination of the bone, ligament, joint, and disc disease, leads to acquired degenerative disease. The lumbar spine is the most commonly affected region, followed by the cervical spine ${ }^{[2]}$. 
Radiographs may provide an inexpensive screening tool of the spine, including osseous detail, alignment, stability, and postoperative evaluation of hardware and fusion. An appropriate initial imaging tool in patients with back pain is a lateral lumbar spine radiograph ${ }^{[3,4]}$.

MDCT provides superior detail of cortical and trabecular bone, fracture, spondylosis, ligamentous ossification, spondylolysis, and facet joint arthropathy with encroaching osteophytes compared with MRI. MRI is more reliable than CT in detecting compressive nerve lesions, although CT can accurately distinguish disk herniations ${ }^{[5]}$.

The superior soft-tissue contrast resolution of MRI has allowed for noninvasive detailed anatomic evaluation of the spine without radiation exposure and is considered the imaging modality of choice for detection of the cause of radicular symptoms versus normal age-related changes. Different pulse sequences applications allow for image acquisition to exploit tissue composition ${ }^{[6]}$. T1-weighted image provides optimal contrast between the internal components of the spinal canal and bright epidural fat.

In general, compared to T1-weighted images, T2weighted images have higher contrast differentiation. Application of short tau inversion recovery (STIR) sequences or Fat-suppression techniques allow more conspicuous detection of marrow edema. Fluid-weighted sequences are useful for visualizing disk desiccation, high-intensity zones, and Modic end-plate changes. Gradient echo sequences allow for delineation of bone and disc margins, providing excellent contrast between the spinal cord and surrounding subarachnoid space and visualization of the exiting cervical nerve roots.

\section{Aims and Objective}

- For characterization of the disc degenerative changes of the lumbar spine using MRI.

- To evaluate the extent of involvement of the degenerative disc disease and its sequelae in the lumbar spine.

\section{Materials and Methods}

Study design: Hospital-based cross-sectional and observational study.

Source of data and Sample Size: 186 patients with low back pain referred from orthopedic and neurosurgery department.

Study Period: The duration of the study was two months from 1st July 2019- 31 August 2019

Study Area: Department of Radio-diagnosis, Konaseema institute of medical sciences and research foundations, Amalapuram, A.P.

Inclusion Criteria: Patients with low back pain referred to the department of Radio-diagnosis, KIMS, Amalapuram, A.P. after obtaining verbal consent.

Exclusion Criteria: We have excluded:

- Pregnant women.

- Patients who underwent recent interventional procedures.

- Post-operative cases.

- Patients with cardiac pacemakers /ferromagnetic aneurysmal clips / metallic orthopedic implants / cochlear implants /intraorbital metallic foreign bodies.

- Severe claustrophobia.

- Subjects unwilling to participate in the study.

- Patients with a history of trauma, prior surgery, spinal infections, active malignancy.

Equipment Used: PHILIPS Achieva 1.5 T MRI machine.

MRI Study Protocol: Sagittal TI-weighted, T2weighted, and axial T2 - weighted, sagittal, and coronal STIR sequences were obtained usingthe standard technique in all the cases. The final report was subsequently compiled by interpretation of above all sequences.

Results: From total 186 patients, 79 patients (i.e.42\% of total patients) were males and 107 patients (i.e.58\% of total patients) were females( Table 1, Fig 1). The most common affected age group was 31 -50 years(Table 2, Fig 2). 


\section{JMSCR Vol||08||Issue||02||Page 298-306||February}

Table 1

\begin{tabular}{|c|c|c|}
\hline \multicolumn{3}{|c|}{ Sex distribution } \\
\hline Sex & No.of Patients & Percentage \\
\hline Males & 79 & $42 \%$ \\
\hline Females & 107 & $58 \%$ \\
\hline
\end{tabular}

Figure 1

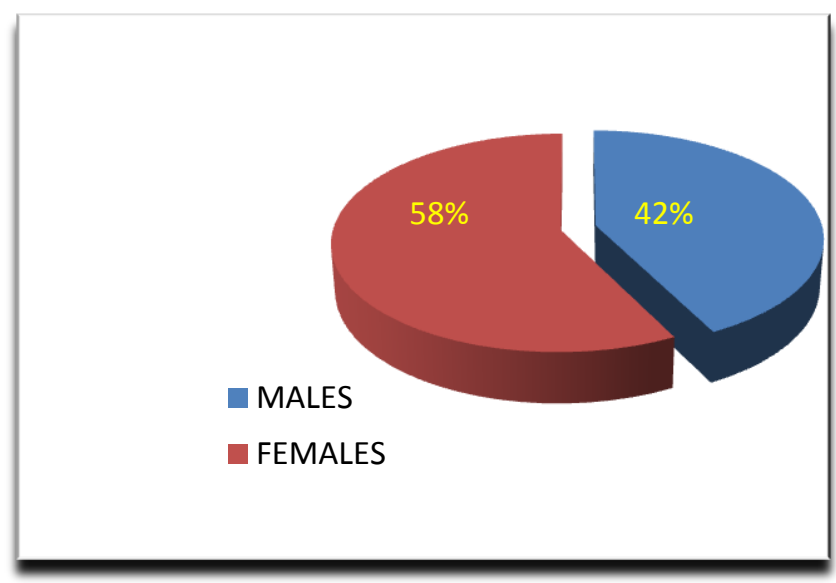

Table 2

\begin{tabular}{|l|c|c|c|}
\hline \multicolumn{4}{|c|}{ Age and Sex Distribution } \\
\hline Age (Yrs) & Males & Females & Total \\
\hline $11-30$ & 14 & 13 & 27 \\
\hline $31-50$ & 35 & 59 & 94 \\
\hline $51-70$ & 29 & 32 & 61 \\
\hline $71-90$ & 01 & 03 & 04 \\
\hline TOTAL & 79 & 107 & 186 \\
\hline
\end{tabular}

Figure 2

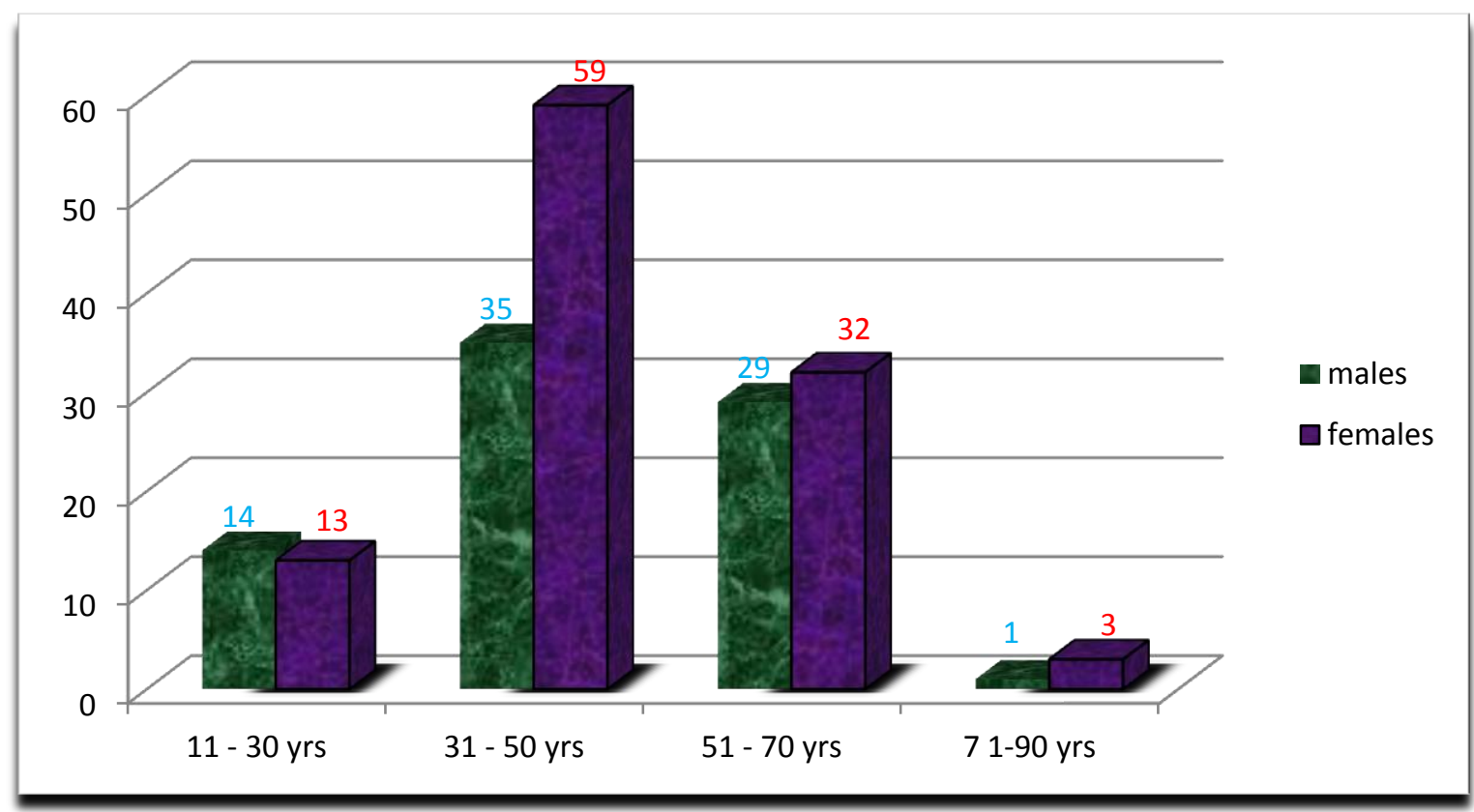


The degenerative changes found in the intervertebral disc levels include disc bulge, disc desiccation changes, annular tears, disc herniation, and vacuum phenomenon with a frequency, as shown in table 3, figure 3,Image 1 .

\section{Table 3}

\begin{tabular}{|l|c|}
\hline Degenerative Changes In Disc \\
\hline Disc Changes & No.of Patients \\
\hline Disc bulge & 186 \\
\hline Annular tear & 94 \\
\hline Disc herniation & 90 \\
\hline Disc desiccation changes & 64 \\
\hline Vacuum phenomenon & 06 \\
\hline
\end{tabular}

Figure 3

\section{Degenerative changes in disc}

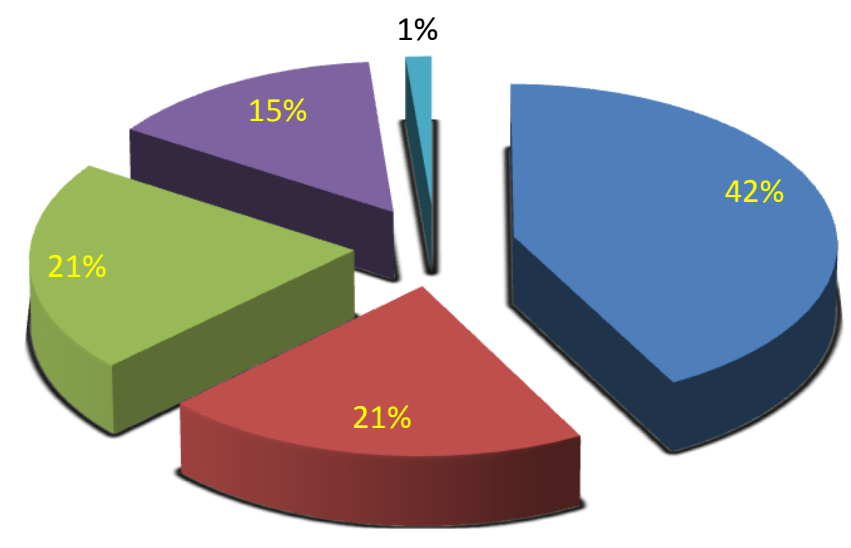

$\square$ Disc Bulge

$\square$ Disc Herniation

$\square$ Annular Tear

Disc desiccation changes

$\square$ Vacuum phenomenon

Disc bulge noted in 562 discs (i.e.60.4\% of disc involvement) with an average of 3 discs involvement per patient. Disc bulge was common at L4 - L5 level (163 patients, i.e., 29\% disc bulge) \& L3 - L4 disc level(152 patients, i.e., $27.04 \%$ disc bulge) as shown in table 4 , figure 4 , Image 1.

\section{Table 4}

\begin{tabular}{|c|c|}
\hline \multicolumn{2}{|c|}{ Disc Level Distribution } \\
\hline Disc Levels & No. of Patients \\
\hline L1 - L2 & 51 \\
\hline L2 - L3 & 92 \\
\hline L3 - L4 & 152 \\
\hline L4 - L5 & 163 \\
\hline L5 - S1 & 104 \\
\hline
\end{tabular}


Figure 4

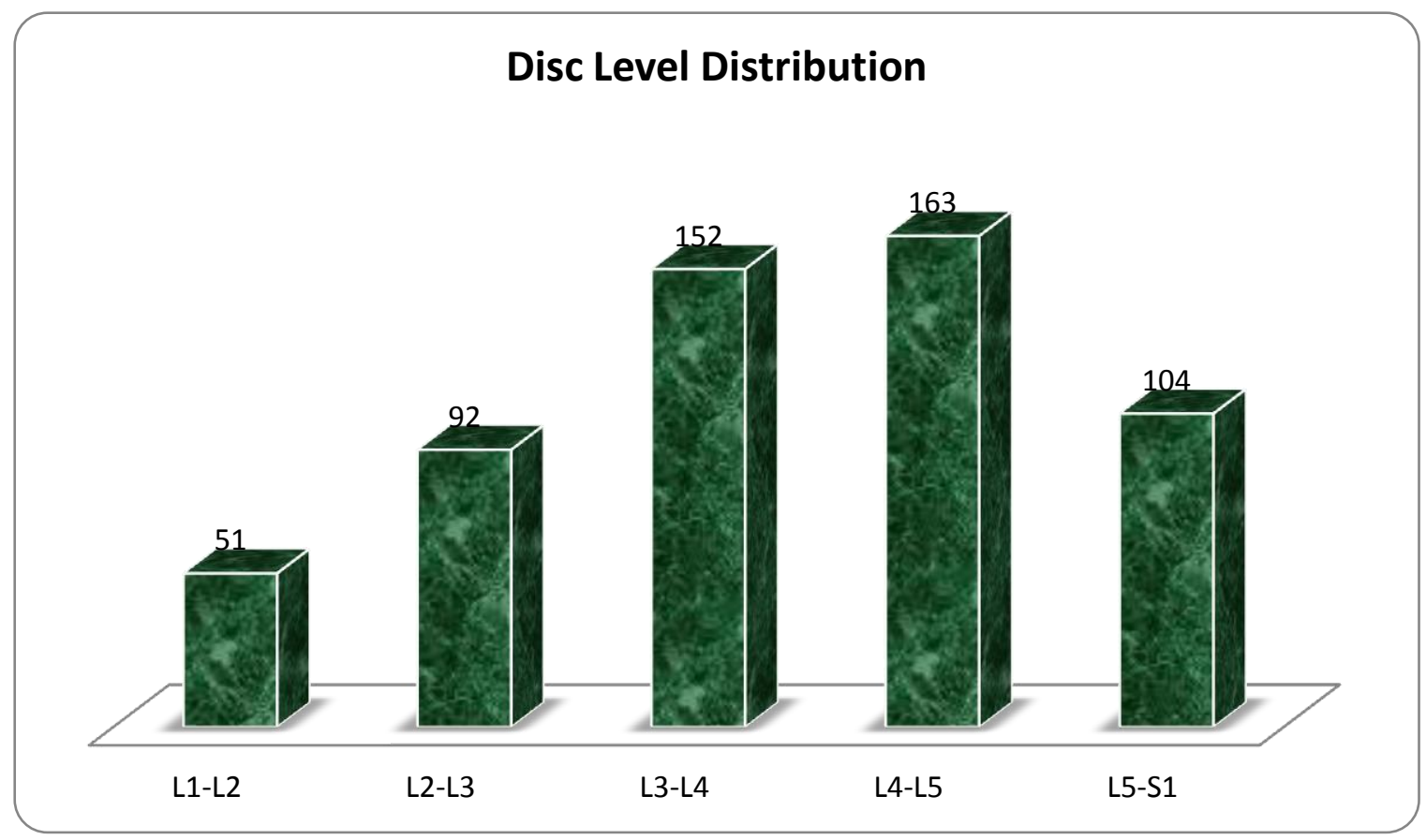

Disc Herniation noted in 134 discs amongst which Protrusion in 128 discs(95.5\% of disc herniations)extrusion in 05 discs (i.e. $3.7 \%$ of disc herniations), and broad-based disc herniation in $01 \operatorname{disc}(0.74 \%)$. Herniation was common at L4 -L5 disc level in 47 patients (i.e., $35.07 \%$ of herniation), Image $1 \& 2$.

Annular tears were found to be in 94 patients (i.e., $50.53 \%$ of total patients) with a preponderance at L4 -L5 disc level(38.75\% of the total, annular tears), Image 1.

Degenerative findings noted in vertebrae were osteophytes, schmorl'snodes(image 6), modic changes, loss of lumbar lordosis, endplate irregularities, and spondylolisthesis with frequencies as shown in table 5, figure 5. Amongst Modic changes, Type II was found to be the most common ( $92 \%$ of modic changes), Image 4.

\section{Table 5}

\begin{tabular}{|l|c|}
\hline \multicolumn{2}{|c|}{ Degenerative Changes In Vertebrae } \\
\hline Vertebral Changes & No.of Patients \\
\hline Osteophytes & 137 \\
\hline Schmorl's Nodes & 96 \\
\hline Modic Changes & 74 \\
\hline Loss of Lumbar Lordosis & 47 \\
\hline Endplate Irregularities & 06 \\
\hline Spondylolisthesis & 30 \\
\hline
\end{tabular}


Figure 5

\title{
Degenerative Changes In Vertebrae
}

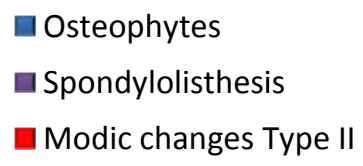

\author{
Schmorl's Nodes \\ 口End Plate Irregularities
}

- Loss of Lumbar Lordosis

口 Modic changes Type III

$\square$ Modic changes Type I

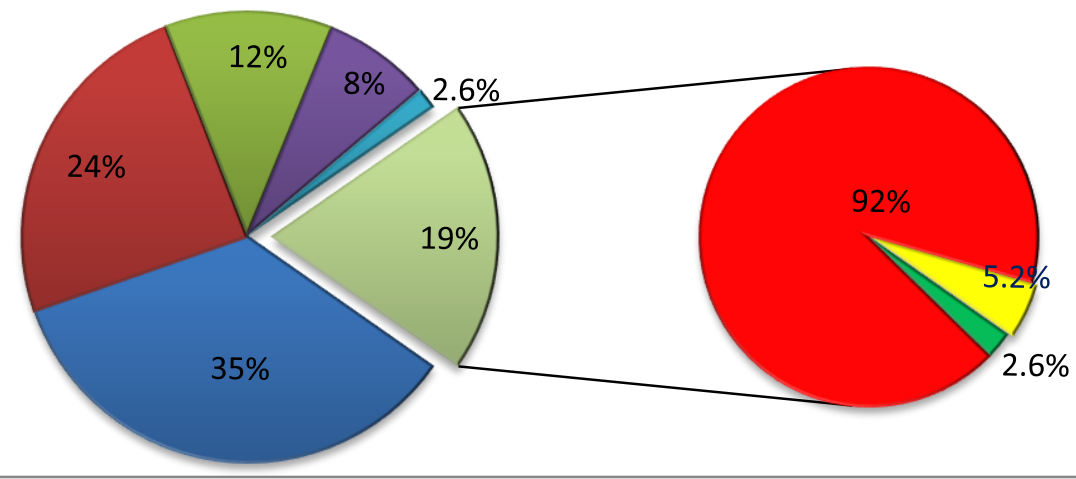

Osteophytes were found to be in 137 patients (i.e., $73.6 \%$ of total patients)(Table 5, figure 5). Facet joint arthropathyand ligamentum flavumthickening were seen in 81 disc levels (i.e., $8.7 \%$ of the disc involvement) \& both were common at the L4 - L5 disc level(Table 6),Image 2.

Lumbar lordosis was maintained in 139 patients $(74.73 \%)$, and loss of the lumbar lordosis was noted in 47 patients $(25.27 \%)$ (Table 5, figure 5), Image 5.
Spondylolisthesis is the form of anterolisthesis or retrolisthesis was found in 30 patients (i.e., $16.12 \%$ of total patients)(Table 6). Anterolisthesis (i.e. $14.5 \%$ of spondylolisthesis) is common as compared to retrolisthesis (i.e. $2.68 \%$ of spondylolisthesis). Listhesis of the L4 vertebral body over the L5 vertebral body was common in both anterolisthesis \& retrolisthesis(Table 5\&6, figure 5, Image 1).

\section{Table 6}

As incidental findings vertebral hemangioma in 67 patients (i.e.

\begin{tabular}{|c|c|c|c|c|c|c|c|c|c|c|}
\hline \multirow{2}{*}{$\begin{array}{c}\text { Inter- } \\
\text { vertebral } \\
\text { Disc Level }\end{array}$} & \multirow{2}{*}{$\begin{array}{l}\text { Disc } \\
\text { Bulge }\end{array}$} & \multirow{2}{*}{$\begin{array}{l}\text { Annular } \\
\text { Tear }\end{array}$} & \multicolumn{3}{|c|}{ Herniation } & \multirow{2}{*}{$\begin{array}{c}\text { Disc } \\
\text { desiccation } \\
\text { changes }\end{array}$} & \multirow{2}{*}{$\begin{array}{l}\text { Ligamentum } \\
\text { Flavum } \\
\text { Hypertrophy }\end{array}$} & \multirow{2}{*}{$\begin{array}{c}\text { Facetal } \\
\text { Arthropathy }\end{array}$} & \multicolumn{2}{|c|}{ spondylolisthesis } \\
\hline & & & Protrusion & Extrusion & $\begin{array}{l}\text { Broad- } \\
\text { Based }\end{array}$ & & & & $\begin{array}{l}\text { Anteroli } \\
\text { sthesis }\end{array}$ & $\begin{array}{c}\text { Retrolis } \\
\text { thesis }\end{array}$ \\
\hline $\mathrm{L} 1-\mathrm{L} 2$ & 51 & 06 & 06 & 00 & 00 & 09 & 00 & 02 & 00 & 00 \\
\hline L2 - L3 & 92 & 13 & 16 & 00 & 00 & 09 & 06 & 03 & 00 & 01 \\
\hline L3 - L4 & 152 & 42 & 25 & 00 & 00 & 20 & 13 & 07 & 01 & 00 \\
\hline L4 - L5 & 163 & 62 & 41 & 05 & 01 & 45 & 21 & 15 & 15 & 02 \\
\hline $\mathrm{L} 5-\mathrm{S} 1$ & 104 & 37 & 40 & 00 & 00 & 37 & 10 & 04 & 10 & 01 \\
\hline
\end{tabular}

$36 \%$ of total patients),Image 7, sacralisation of L5 vertebra in 23 patients (i.e.,12.3\% of total patients) scoliosis and tarlov Cyst in 06 patients (i.e.,3.2\% of total patients), lumbarisation of S1 in one patient (i.e.0.53\% of total patients) were found(Table 7,figure 6).
Table 7

\begin{tabular}{|l|c|}
\hline Incidental Findings \\
\hline Findings & No. of Patients \\
\hline Hemangiomas & 67 \\
\hline Sacralisation of L5 vertebra & 23 \\
\hline Scoliosis & 06 \\
\hline Tarlov Cyst & 06 \\
\hline Lumbarisation of S1 & 01 \\
\hline
\end{tabular}




\section{Figure 6}

\section{Incidental Findings}

- Incidental Findings

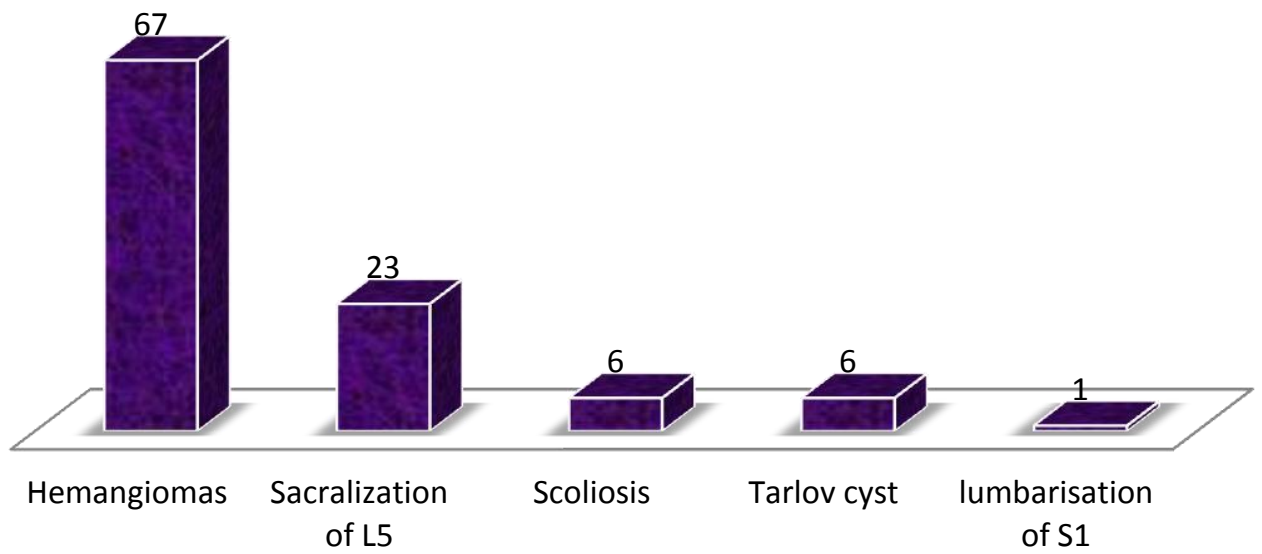

\section{Discussion}

In our study female preponderance of degenerative disease in intervertebral discs of the lumbar spine was seen, while male preponderance was found in the study done by Suthar $\mathbf{P}$, et al. in $2015^{[7]}$

In a retrospective study by Verma et al. in 2011, the L4-L5 level, followed by the L5-S1 level, was found to be the most common levels showing degenerative changes while in our study L4-L5 followed by L3-L4 were found to be most common $^{[8]}$.
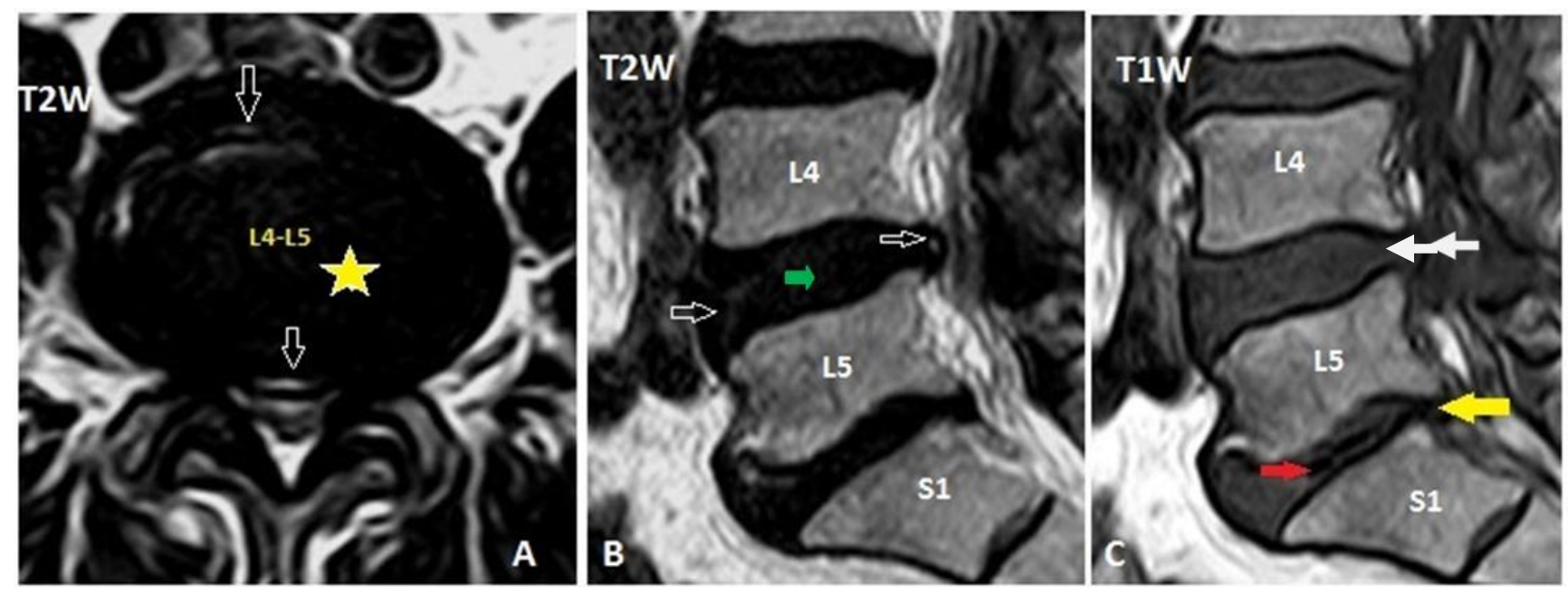

Image 1 showing generalized disc bulge( $\lesssim$ ), Annular tear $(\Rightarrow)$ ), Disc herniation(solid white arrow), Disc desiccation changes $(\rightarrow$ ), Vacuum phenomenon(red arrow),spondylolisthesis(yellow arrow) in axial $\mathrm{T} 2 \mathrm{~W}(\mathrm{~A})$,sagittal T2W(B) and T1W(C) images. 


\section{JMSCR Vol||08||Issue||02||Page 298-306||February}

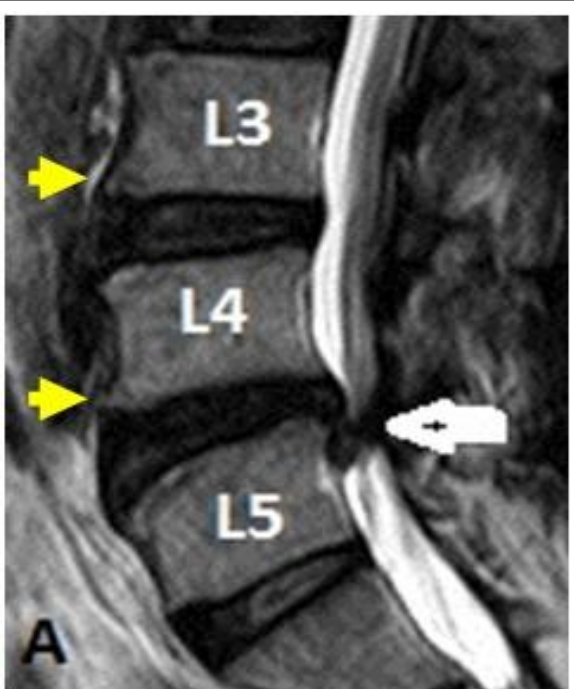

Image 2 depicts osteophytes(yellow arrow) and disc extrusion(white arrow) in sagittal T2W image

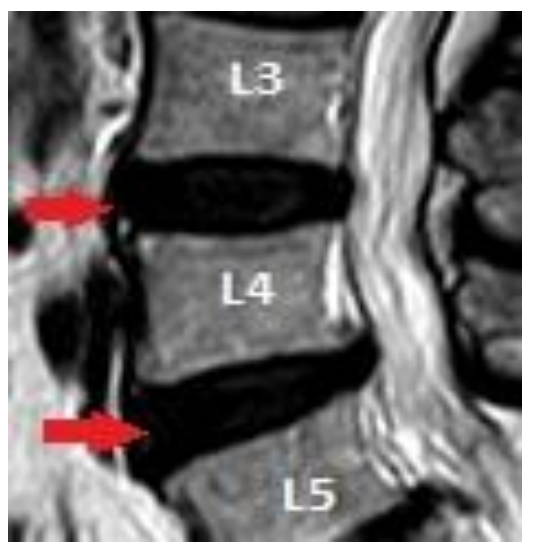

Image 3 showing disc desiccation changes in L3L4 and L4-L5 intervertebral disc level in T2W sag image (red arrows)

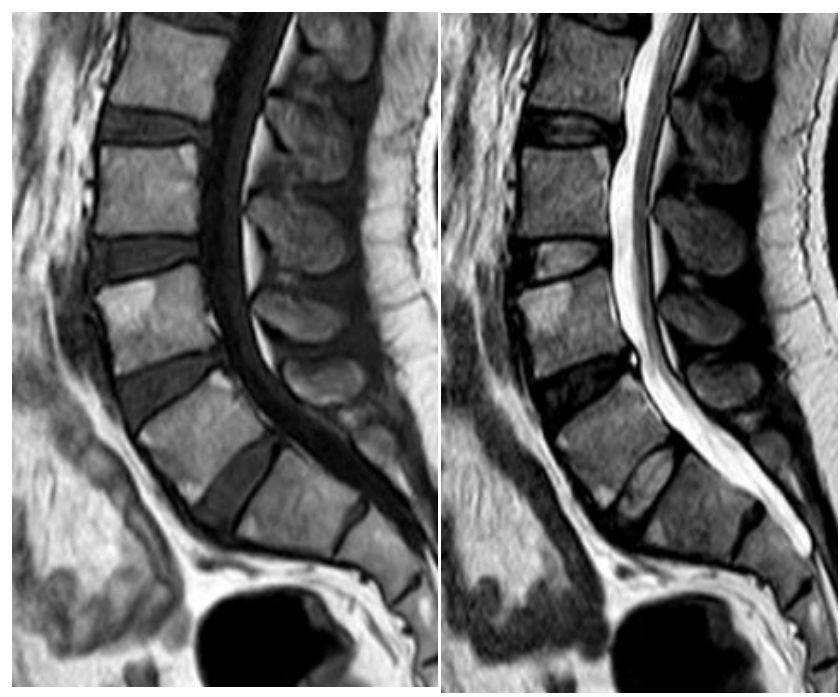

Image 4: Type II Modic endplate changes showing sagittal T1W(A) and T2W(B) hyperintensities along the subchondral endplates.

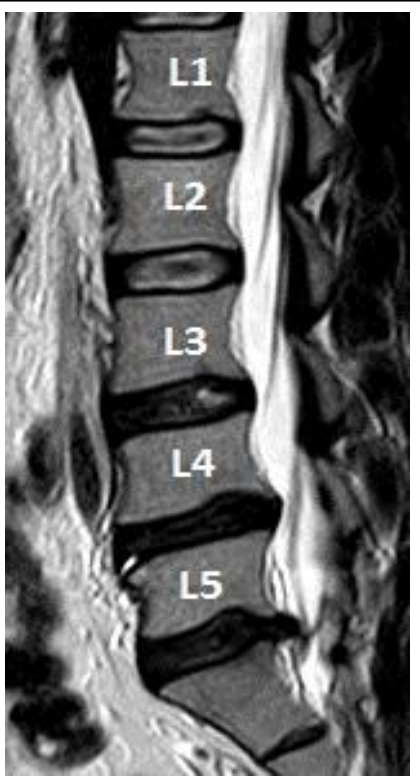

Image 5 depicting loss of normal lumbar lordosis in sagittal T2 weighted MRI sequence

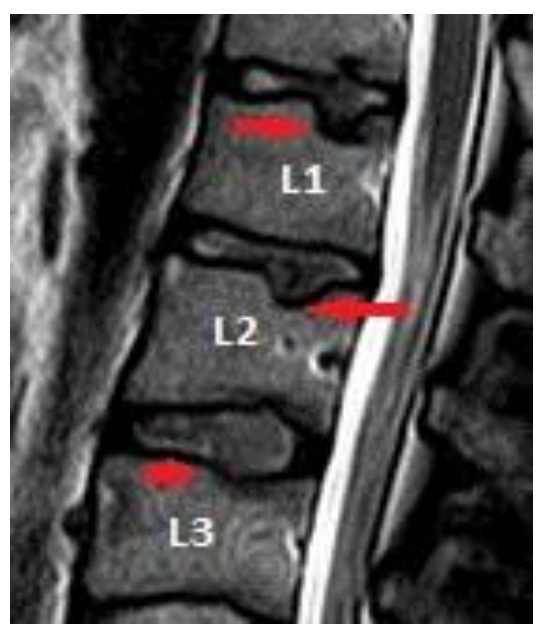

Image 6 showing multilevel Schmorl's nodes (red arrows) in sagittal T2W images.

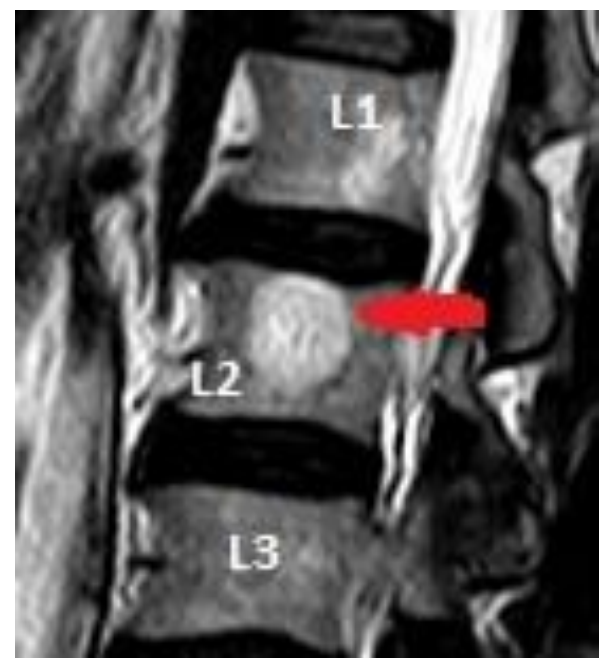

Image 7 depicting hemangioma in $\mathrm{T} 2 \mathrm{~W}$ sequences (red arrow). 


\section{Conclusion}

Degenerative changes in the lumbar spine were found to be the most common culprit for low back pain, especially in the age group of 31 to 50 years with a female preponderance. The most common disc level involved in disc bulges, disc herniations, disc desiccation changes, ligamentum flavum hypertrophy, facet joint arthropathy, annular tears, and spondylolisthesis was found to be L4-L5. Endplate irregularities, vacuum phenomenon, and broad-based herniation were found less common. Amongst all the lumbar disc levels, degenerative changes, least commonly involved in the L1-L2 level. For characterization of degenerative changes in the lumbar spine leading to low back pain due to its superior delineation of soft tissue and radiation-free imaging, the MRI is the modality of choice.

\section{References}

1. Maus TP: Imaging of spinal stenosis: Neurogenic intermittent claudication and cervical spondylotic myelopathy. Radiol Clin North Am 50(4):651-679, 2012.

2. Jacobs DS: Degenerative diseases of the spine. Haaga: CT and MRI of the Whole Body, ed 5, St. Louis, 2008, Mosby, pp 755-799.

3. Hammouri QM, Haims AH, et al: The utility of dynamic flexion-extension radiographs in the initial evaluation of the degenerative lumbar spine. Spine (Phila $\mathrm{Pa}$ 1976) 32(21):2361-2364, 2007.

4. Khalil JG, Nassr A, Maus TP: Physiologic imaging of the spine. Radiol Clin North Am 50(4):599-611, 2012.

5. Van Rijn JC, Klemetso N, Reitsma JB, et al: Observer variation in the evaluation of lumbar herniated discs and root compression: Spiral CT compared with MRI. Br J Radiol79:372-377, 2006.
6. Carrino JA, Morrison WB: Imaging of lumbar degenerative disc disease. Semin Spine Surg 15(4):361-383, 2003.

7. Suthar P, Patel R, Mehta C, Patel N. MRI evaluation of lumbar disc degenerative disease. Journal of clinical and diagnostic research: JCDR. 2015 Apr;9(4): TC04.Verma SR, Gupta PK, Munshi A, Goyal P, Verma SC, Sardana V.

8. A Retrospective Analysis Of Magnetic Resonance Imaging Findings In 20-40 Year Old Patients With Low Back Pain. Experience At A Semi Urban Tertiary Healthcare Centre In Northern India. The Internet Journal of Spine Surgery. 2011;6(4):1937-8270.

9. Yong PY, Alias NN, Shuaib IL. Correlation of clinical presentation, radiography, and magnetic resonance imaging for low back pain-A preliminary survey. JOURNAL-HONG KONG COLLEGE OF RADIOLOGISTS. 2003;6:144-51.

10. Osman NM, Fawzy FM, Lateef HM. MRI Evaluation of Lumbar Disc Degenerative Disease. Egyptian Journal of Hospital Medicine. 2017 Jul 30;68(2). 